course of celebration, it occurred, I believe, to some influential members of the Institution of Electrical Engineers that the terms on which their membership was granted would perhaps have excluded Faraday himself. We may look on the present award as a healthy reaction from that state of things. It shows that the bodies making the award are animated by no narrow spirit of professionalism. The doctors learnt much from Pasteur, though he was not a member of their profession. Similarly, the engineers have learnt much from J. J. Thomson.

Let me remind you of some of it ; and let me say that I am not speaking from book knowledge, still less from hearsay. I was working in the Cavendish Laboratory when many of the things were done, and I saw them in progress. The professor was very much the reverse of a mystery man-he told us freely of his half-formed ideas, and even allowed us to argue with him about them. For example, he was much exercised about the nature of cathode rays, the properties of which had been so well described by Hittorf, Crookes, Goldstein, and Lenard. Were they a stream of electrified particles, or were they not? At first the only fact with a really clear bearing on this question was the magnetic deflection. Thomson was one of those who saw most clearly the full strength of this argument. But he saw that there ought to be an electrostatic deflection as well, when a transverse electromotive force was applied; and that did not seem to happen. Why not? Thomson wondered whether the electromotive force really was being fairly applied. He found that the cathode rays made the residual gas in the vessel very eonductive. The result of this was that all the applied voltage was ineffectively dropped on the space near the transverse electrodes where the rays were not. The remedy for this was to have as little gas as possible. High vacua were not so easily made then as they are now. However, the difficulty was overcome, and the transverse deflection observed.

What has all this got to do with engineering? Well, take the cathode ray oscillograph, the tool of the electrical engineer for dealing with all problems concerning rapid surges of current and potential. What is this but a glorified edition of the apparatus with which Thomson observed the electrostatic deflection of cathode rays, and discovered the electron ? Again, take television. Does not cathode ray television depend on the use of electrostatic deflection to cause the cathode beam to scan the picture? If we did not know that the cathode rays were charged particles, should we have known how to retard them by longitudinal electric forces, so as to modify the energy, and produce the light and shade of the picture?

I have taken a few direct examples coming immediately from Thomson's own researches. But his services to engineering by no means end with them. There can be little doubt that his early writings on electric waves and oscillations were a main source of inspiration to those who were concerned with the development of wireless and of high-frequency electrical engineering generally. Before he turned his attention to electric discharge phenomena, there was so far as I can recall no systematic treatment of the subject, and when it came to the development of the three electrode valve, and the various forms of electric discharge lamps which now light our streets, it was to Thomson's writings that the inventor turned for guidance.

\title{
William Herbert and Amaryllis Culture
}

" $\mathrm{H}^{\mathrm{s}}$ ERBERT bridges the gap not only between Ray and Darwin but also between Kölreuter and Mendel," writes Dr. C. D. Darlington in "Herbertia", the year-book of the American Amaryllis Society for $1937^{1}$. The Hon. and Rev. William Herbert was for thirty-three years rector of Spofforth in Yorkshire. He published, in 1837, a volume on the Amaryllidaceæ, which must still be consulted by any serious student of the genus, and fully warrants the Society's choice of the title "Herbertia" for its year-book. An addendum to Herbert's volume of 1837, entitled "On Crosses and Hybrid Intermixtures in Vegetables" was, moreover, a classic which fully justifies Dr. Darlington's estimate. The text appears in the 1937 "Herbertia" and should be read for its historical value as a portrayal of early work on conscious hybridization.

Few year-books achieve such monographic treatment as "Herbertia". Full consideration is given to the Society's affairs and regional activities, but there are also numerous original articles, and an intensive system of review paragraphs. The main contribution in the section on description and phylogeny is by Spencer Savage, and concerns a manuscript by the younger Linnæus dealing with certain genera now included in the Amaryllidaceæ. W. S. Flory and

${ }^{1}$ From the Editor, Dr. Hamilton P. Traub, Mira Flores, Orlando, Florida, U.S.A. Pp. 272. Oct. 1937.
S. H. Yarnell contribute a comprehensive review of chromosome numbers in the Hemerocallideæ, Alstromeriales and Amaryllidales, whilst Friedrich Meyer describes a new daffodil mutation, Narcissus schizo. coronatus. Many other accounts of particular crosses also appear.

The section on the physiology of reproduction contains papers on the effect of growth substances on Hippeastrum, Hemerocallis and Alstromeria by Dr. Hamilton P. Traub, the editor, who also writes on new methods of propagating Hemerocallis. The tender crown tips are severed and then cut longitudinally into halves or quarters, which are capable of rooting in a sandy medium. Mr. Wyndham Hay. ward, secretary to the Society, has also shown that the portion of rhizome remaining after the crown has been severed can be induced to form four or five shoots, which can later be propagated as separate plants. H. H. Hume and J. V. Watkins have a paper on propagation of Zephyranthes by various methods of cutting the root plate of the bulb.

Very numerous papers on amaryllid culture appear, and a small section on harvesting, storage and forcing is to be expanded to greater dimensions next year. No narrow national limits are interpreted into the Society's title, and one cannot but be grateful for its international scope and appeal. 